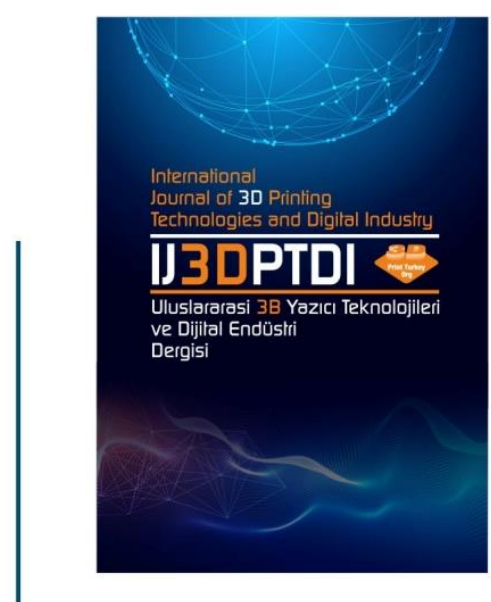

ULUSLARARASI 3B YAZICI TEKNOLOJILERI

VE DIJITAL ENDÜSTRI DERGISI

INTERNATIONAL JOURNAL OF 30 PRINTING TECHNOLOGIES AND DIGITAL INDUSTRY

I55N:2602-3350 [Online]

URL: https://dergipark.org.tr/ij3dptdi

\title{
INVESTIGATION OF THE EFFECT OF HEAT TREATMENT CONDITIONS ON HARDNESS PROPERTIES OF MARAGING STEELS PRODUCED BY ADDITIVE MANUFACTURING
}

Yazarlar (Authors): İlkgül Öksüzcan ${ }^{D}$, Derya Çakan ${ }^{D}$, Mustafa Safa Yılmaz ${ }^{D *}$, Onur Ertuğrul iD

Bu makaleye şu şekilde atıfta bulunabilirsiniz (To cite to this article): Öksüzcan l., Çakan D., Yılmaz M.S., Ertuğrul O., "Investigation Of The Effect Of Heat Treatment Conditions On Hardness Properties Of Maraging Steels Produced By Additive Manufacturing", Int. J. of 3D Printing Tech. Dig. Ind., 5(3): 654-662, (2021). 


\title{
INVESTIGATION OF THE EFFECT OF HEAT TREATMENT CONDITIONS ON HARDNESS PROPERTIES OF MARAGING STEELS PRODUCED BY ADDITIVE MANUFACTURING
}

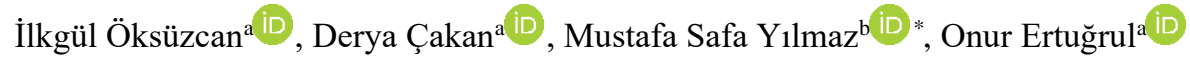 \\ ${ }^{a}$ İzmir Katip Çelebi Üniversity, Dept. Materials Science and Eng., İzmir, TURKEY \\ ${ }^{\mathrm{b}}$ Fatih Sultan Mehmet Vakif University, Faculty of Engineering, Istanbul, TURKEY \\ *Correponding Author: m.safayilmaz@gmail.com
}

(Received: 16.11.2021; Revised: 05.12.2021; Accepted: 26.12.2021)

\begin{abstract}
Additive Manufacturing (AM) technology produces parts in layers and offers design freedom (3D design), zero waste, reduced expensive tool material requirements, and improved mechanical properties. Maraging steels have superior strength and toughness with adequate ductility. The effect of aging process parameters on the final properties of AM Maraging steels is enormous. In this study, the effects of heat treatment atmospheres and temperatures to the direct metal laser sintered (DMLS) maraging steels were examined. Aging heat treatment was applied in different atmospheres $\left(\mathrm{Ar} / \mathrm{H}_{2}\right.$ and air) and temperatures $\left(490^{\circ} \mathrm{C}, 520^{\circ} \mathrm{C}, 550^{\circ} \mathrm{C}, 580^{\circ} \mathrm{C}\right)$. SEM and XRD devices were used to examine the microstructure properties, and Vickers hardness device was used to determine the mechanical properties. When the results are evaluated, it was observed that the increased temperature after $490{ }^{\circ} \mathrm{C}$ adversely affected the hardness value. XRD analysis showed martensite and austenite phases in air and $\mathrm{Ar} / \mathrm{H}_{2}$ atmospheres. According to the SEM images, it can be said that the traces of the melt pool remaining from the AM disappear with the increasing temperature in general.
\end{abstract}

Keywords: Additive Manufacture, Heat Treatment, Maraging Steel

\section{INTRODUCTION}

Additive manufacturing (AM) is a production method that can produce three-dimensional objects with a computer. Additive manufacturing can produce complex geometric shapes using 3D object scanners or computer-aided design (CAD) without the need secondary processing [1]. In the traditional production method, excess material needs to be removed, such processes are not required in additive manufacturing. This technology produces parts in layers and offers design freedom (3D design), zero waste, reduced expensive tool material requirements, and improved mechanical properties [1]. Today, this technology is widely used in the automotive and mould industries, especially in the aviation and medical industries. Other important applications where AM technology is used are; gas turbine blades, turbo exchanger rotors and heat exchangers [2]. The variety of materials that can be used for the additive manufacturing process is currently increasing. The solid, liquid and gas-based raw materials are used to manufacture parts in AM technologies. The additive manufacturing technologies are determined according to the form of the material used to build raw material. Most of the metal powders used in the additive manufacturing method are generally produced using well-known technologies for metal powder production [3]. The most used processes in the AM technology of metal-based parts are Powder Bed Fusion (PBF) processes.

The selective laser melting (SLM) method, which is one of the powder bed melting processes, metal powders are successfully melted by the laser. The CAD 3D file dictates where the melting occurred. Thus, the particles in the determined regions are melted by the laser. After the thin metal powders laid on the layer are melted by the laser, the machine successfully applies the same process again until the product completed [4]. Among the different AM processes, selective laser melting which is a technology based on powder bed fusion, selects regions of the powder bed and melts it with thermal energy.[5]. Different machine manufacturers have taken other names during patent applications, 
especially the laser powder bed melting process. While EOS company names this additive manufacturing technique DMLS (Direct Metal Laser Sintering), the same technique is also called SLM (Selective Laser Melting), LS (Laser sintering) or SLS (Selective Laser Sintering) systems used for polymer materials [6].

Maraging steels are known for possessing superior strength and toughness without losing ductility. Maraging steels are alloys with nanometer-sized intermetallic deposits homogeneously distributed in a martensitic matrix as microstructure and thus gain high strength-high toughness mechanical properties [4]. In addition, its relatively low carbon content gives these materials good weldability, making it one of the most preferred materials in metal additive manufacturing. Maraging steel is used in complex and smart cooling channels in processes such as injection and extrusion, especially in the molding sector. Complex-shaped molds with conformal cooling channels formed by assembling three or more parts in traditional manufacturing can be produced at once with AM technology [7]. Heat treatment processes are also applied to maraging steel parts produced with additive manufacturing technology. Because the effect of heat treatment and selection of heat treatment parameters on the microstructure of AM materials and thus on product performance is enormous, especially nowadays, studies on this subject are increasing rapidly. In addition, after heat treatment is applied to maraging steels, residual stresses on the structure's surface disappear [8]. Stress-relieving processes can be applied to remove residual stress from the additive manufacturing process. In a study by I. Adam et al., a 3-hour heat treatment was applied at a temperature of $890{ }^{\circ} \mathrm{C}$ for stress relief before the aging process. Similar values were found when the resulting alloy properties were compared to supplier EOS's [9]. Plasma nitriding can also be applied as another heat treatment method. In the study of Adriano et al., aging heat treatment and nitriding applied at the same time of Maraging 300 steel was happened in a DC pulsed plasma nitriding reactor. Since the plasma nitriding and aging processes took place at the same temperature and time intervals, a single heat treatment cycle was performed. Aging and plasma nitriding performed at $480{ }^{\circ} \mathrm{C}$ for 3 hours. The heat treatment produced case depths of $50 \mu \mathrm{m}$, as $\varepsilon$ $\mathrm{Fe} 3 \mathrm{~N}$ and $\gamma^{\prime}$-Fe4N nitrides were formed in the hardened surface layer and increased the surface hardness reached $1140 \mathrm{HV}$ [10]. In recent years, a lot of work has been done to determine the aging heat treatment (T5-like heat treatment) or T6 heat treatment (solution taking, quenching artificial aging), which are carried out to improve the mechanical properties of maraging steel alloy parts. They applied various heat treatments to evaluate the microstructure, hardness, tensile properties and plastic tensile behavior of maraging steel on plastic anisotropy and mechanical properties combined with time and temperatures.

In a study by Yuchao Bai et al., many heat treatments were applied at different temperatures and at different times. These are the solution, the aging process, and the successive soaking and aging process. As a result of the heat treatments, the sample with the most suitable mechanical properties is the 6-hour aging heat treatment at $520{ }^{\circ} \mathrm{C}$ [11]. This study by Mooney et al. shows the tensile mechanical properties and anisotropy levels of identical test coupons manufactured from maraging steel 300 (MS300) using two alternative EOS EOSINT M290 Additive Manufacturing (AM) systems were investigated. Mechanical performance variations due to process differences between the two suppliers and the build volume orientation of the part $\left(0^{\circ}, 45^{\circ}\right.$ and $\left.90^{\circ}\right)$ are investigated. A difference in the angle of the laser scanning strategy appears to have a profound effect on the plasticity and anisotropy differences observed in the AM MS300 alloy, in conjunction with unfavourable powder feedstock properties. Plastic anisotropy levels can be greatly reduced through practice. However, some degree of transverse strain anisotropy is likely to remain due to aging heat treatments, manufacturing history of the AM alloy [8].

In this study, aging heat treatment (T5 heat treatment) was applied to maraging steel samples produced by DMLS technique at different temperatures $\left(490{ }^{\circ} \mathrm{C}, 520^{\circ} \mathrm{C}, 550^{\circ} \mathrm{C}, 580^{\circ} \mathrm{C}\right)$ and atmosphere $\left(\mathrm{Ar} / \mathrm{H}_{2}\right.$ gas and air). The reason for choosing different temperatures in this study; some researchers stand on the effect of conventional heat treatments suitable for cast and forged steel samples. This is because traditional casting and forging processes emerged in the 1850s, while the AM process began to be used in the 1980s. While quite large parts can be produced with traditional methods, the limitedness of AM has led the industry to conventional methods. Based on the literature review, the microstructure 
and micro weathering of maraging steel parts produced with the DMLS technique are different from cast or forged parts. Complex parts can be easily produced, while parameters such as laser power, scanner speed and layer thickness can be adjusted, but not in the traditional method. The effects of maraging steel samples produced by DMLS technique on their mechanical properties were investigated by applying heat treatment at different temperatures. $\mathrm{Ar} / \mathrm{H}_{2}$ gas was used to prevent oxidation in the air atmosphere. In this case, the changes in the structure of the $\mathrm{Ar} / \mathrm{H}_{2}$ gas and the air atmosphere were compared.

\section{MATERIAL AND METHOD}

\subsection{Materials}

Commercially available maraging 300 steel powder was used. The chemical composition, including the amounts of impurities, was determined using chemical analysis, and is shown in Table 1. Maraging steels are alloys that have nanometer-sized intermetallic precipitates homogeneously distributed in a martensitic matrix and thus gain high strength-high toughness mechanical properties [9]. The mechanical properties are shown in Table 2.

Table 1: Chemical composition of the maraging 300 steel (wt. \%) [12].

\begin{tabular}{cccccccc}
\hline \hline Element & $\mathbf{N i}$ & $\mathbf{C o}$ & $\mathbf{M o}$ & $\mathbf{T i}$ & $\mathbf{A l}$ & $\mathbf{C}$ & $\mathbf{F e}$ \\
\hline \hline $\boldsymbol{\%}$ & $17-19$ & $8,5-9,5$ & $4,5-5,2$ & $0,6-0,8$ & $0,05-0,15$ & $<0.03$ & Bal. \\
\hline \hline
\end{tabular}

Table 2: Achievable maximum mechanical properties of maraging steels after optimum heat treatments [13].

\begin{tabular}{|c|c|c|c|c|}
\hline Grade & $\begin{array}{c}\text { Yield } \\
\text { Strength } \\
(\mathbf{M P a})\end{array}$ & $\begin{array}{c}\text { Tensile } \\
\text { Strength } \\
(\mathbf{M P a})\end{array}$ & $\begin{array}{c}\text { Elongation } \\
(\mathbf{\%})\end{array}$ & $\begin{array}{c}\text { Fracture } \\
\text { Toughness } \\
(\mathbf{M P a} \sqrt{ } \mathbf{m})\end{array}$ \\
\hline $18 \mathrm{Ni200}$ & 1400 & 1500 & 10 & $155-240$ \\
\hline $18 \mathrm{Ni} 250$ & 1700 & 1800 & 8 & 120 \\
\hline $18 \mathrm{Ni300}$ & 2000 & 2050 & 7 & 80 \\
\hline $18 \mathrm{Ni350}$ & 2400 & 2450 & 6 & $35-50$ \\
\hline $18 \mathrm{Ni}(\mathrm{Cast})$ & 1650 & 1750 & 8 & 105 \\
\hline Cobalt-free 18Ni250 & 1825 & 1895 & 11.5 & 127 \\
\hline Low-cobalt 18Ni250 & 1780 & 1835 & 11 & 149 \\
\hline
\end{tabular}

\subsection{Production Process}

DMLS technology, like other 3D technologies, goes through 3 stages, respectively, printing model, layer by layer production. The 3D model is created, the code is given to the printer with the appropriate software, and the physical process is started. The spherical maraging $18 \mathrm{Ni} 300$ powder was filled into the feeding hopper. Production parameters are at room temperature, scanning speed is $360 \mathrm{~mm} / \mathrm{s}$, laser power is $280 \mathrm{Watt}$, the layer thickness is $30 \mu \mathrm{m}$. These parameters are recommended by EOS (DMLS manufacturer) and the literature. The part to be created begins by distributing a thin layer of metal powder onto the build platform. The dispersed powder is scanned by the laser and selectively sinters the powder into a solid. The layering and sintering sequence continues until the part is complete. The DMLS device is shown in Figure 1. After the part is allowed to cool, loose metal dust around it is removed from the printer [14]. In this study, the samples produced by the additive manufacturing method are ready for heat treatment by metallographic methods. A total of 5 cubic samples $(13 \times 13 \times 13 \mathrm{~mm})$ were produced. 


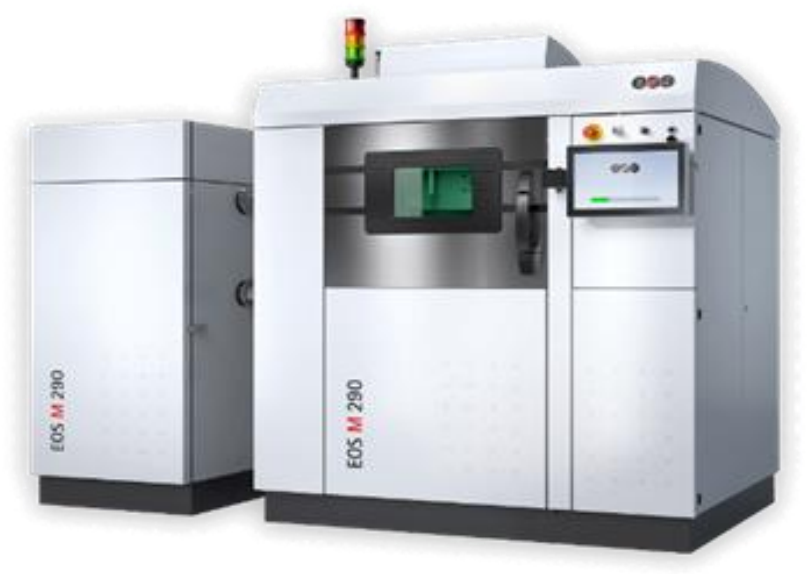

Figure 1: DMLS machine [14].

\subsection{Aging Heat Treatment Process}

The aging heat treatment was performed in an atmosphere controlled tube furnace of Protherm brand. A glass tube made of quartz was used as the tube. The heating rate was set at $6{ }^{\circ} \mathrm{C} / \mathrm{min}$. The gas pressure was controlled by a manometer during the aging heat treatment process, and a pressure that exceeded atmospheric conditions was avoided. The most important point is the flow rate of the gas passing through the tube, set as 2-3 L/min. Two different atmospheres were used: $90 \% \mathrm{Ar}-10 \% \mathrm{H}_{2}$ gas mixture and air. The temperatures are $490^{\circ} \mathrm{C}, 520^{\circ} \mathrm{C}, 550^{\circ} \mathrm{C}, 580^{\circ} \mathrm{C}$ and aging heat treatment process was applied in 6 hours. In the air atmosphere, it was aged for 6 hours at $490^{\circ} \mathrm{C}$. When we compare our study with a similar study by Stornelli et al., it shows similar hardness values with samples heat treated at $490^{\circ} \mathrm{C}$ for 6 hours. In this case, it was observed that the solution heat treatment had no effect on the hardness results[15]. In addition, eos company recommends direct aging at $490^{\circ} \mathrm{C}$ for 6 hours[16]. The applied aging heat treatment parameters and atmospheres are shown in Table 3.

Table 3: Heat treatment parameters of maraging steel.

\begin{tabular}{ccc}
\hline \hline \multicolumn{3}{c}{ Heat Treatment Process } \\
\hline \hline Atmosphere & Temperature $\left({ }^{\circ} \boldsymbol{C}\right)$ & Time $(\boldsymbol{h})$ \\
\hline \hline $\mathrm{Air}$ & 490 & 6 \\
$\mathrm{Ar} / \mathrm{H}_{2}$ & 490 & 6 \\
$\mathrm{Ar} / \mathrm{H}_{2}$ & 520 & 6 \\
$\mathrm{Ar} / \mathrm{H}_{2}$ & 550 & 6 \\
$\mathrm{Ar} / \mathrm{H}_{2}$ & 580 & 6 \\
\hline \hline
\end{tabular}

\subsection{Sample Preparation}

The sample preparation process is important. Because to get the most accurate data from the characterization processes, the sample's surface must be smooth. We carried out our sample preparation using the metallographic method. We first molded our heat-treated samples and then subjected them to sanding and polishing, respectively. Sanding is for reducing coarse defects and polishing is for reducing fine imperfections. 0.25 and 3-micron diamond solution was used during the polishing process. Lubricant, which stops the polishing process, reduces friction, and prevents the formation of deep scratches. Initially, a 3-micron diamond solution and a lubricant were used together. Then 0.25-micron diamond solution and lubricant were then used. Finally, polished samples were etched with the 1,5\% nital and then rinsed with running water and ethanol. Subsequently, samples were dried by air blowing. In a similar study, the last operation was done in the same way [17]. Thus, the samples were made ready for further processing.

\subsection{Characterization Analysis}

Scanning electron microscopy (SEM), X-Ray diffraction (XRD), optical microscopy (OM), Hardness test and Archimedes methods were used for characterization analysis. The X-ray diffraction method (XRD) is based on the principle that each crystal refracts X-rays in a characteristic pattern, depending on the phase's unique atomic arrangement. In this study, Empyrean brand XRD device was used to 
determine the phases.Hardness tests were measured with Inpros brand hardness device. At least five Vickers hardness measurements at $1 \mathrm{~kg}$ weight were made for 10 seconds from each sample. Eclipse E200 Nikon brand was used in optical microscope for microstructure analysis.

\section{RESULTS AND DISCUSSIONS \\ 3.1 Optical Microscopy Results}

Figure 3 shows the microstructure of the heat-treated samples at $490{ }^{\circ} \mathrm{C}$ in the air and $\mathrm{Ar} / \mathrm{H}_{2}$ atmosphere. When we look at the microstructures of these two atmospheres, molten pools from additive manufacturing appear. Both have similar microstructural features. Figure 3.3 (e-d) shows the microstructures of the heat-treated samples at $520^{\circ} \mathrm{C}, 550^{\circ} \mathrm{C}$ and $580^{\circ} \mathrm{C}$, respectively, in the $\mathrm{Ar} / \mathrm{H}_{2}$ atmosphere. With the increasing temperature, it can be said that the traces of the molten pool are gradually decreasing and almost disappear at $580{ }^{\circ} \mathrm{C}$. Gökhan O. et al., in a similar study, commented as follows; When it is examined at the microstructure of the as-built sample and the aged sample, they observed that the melt pools partially disappeared after the ageing heat treatment [13].

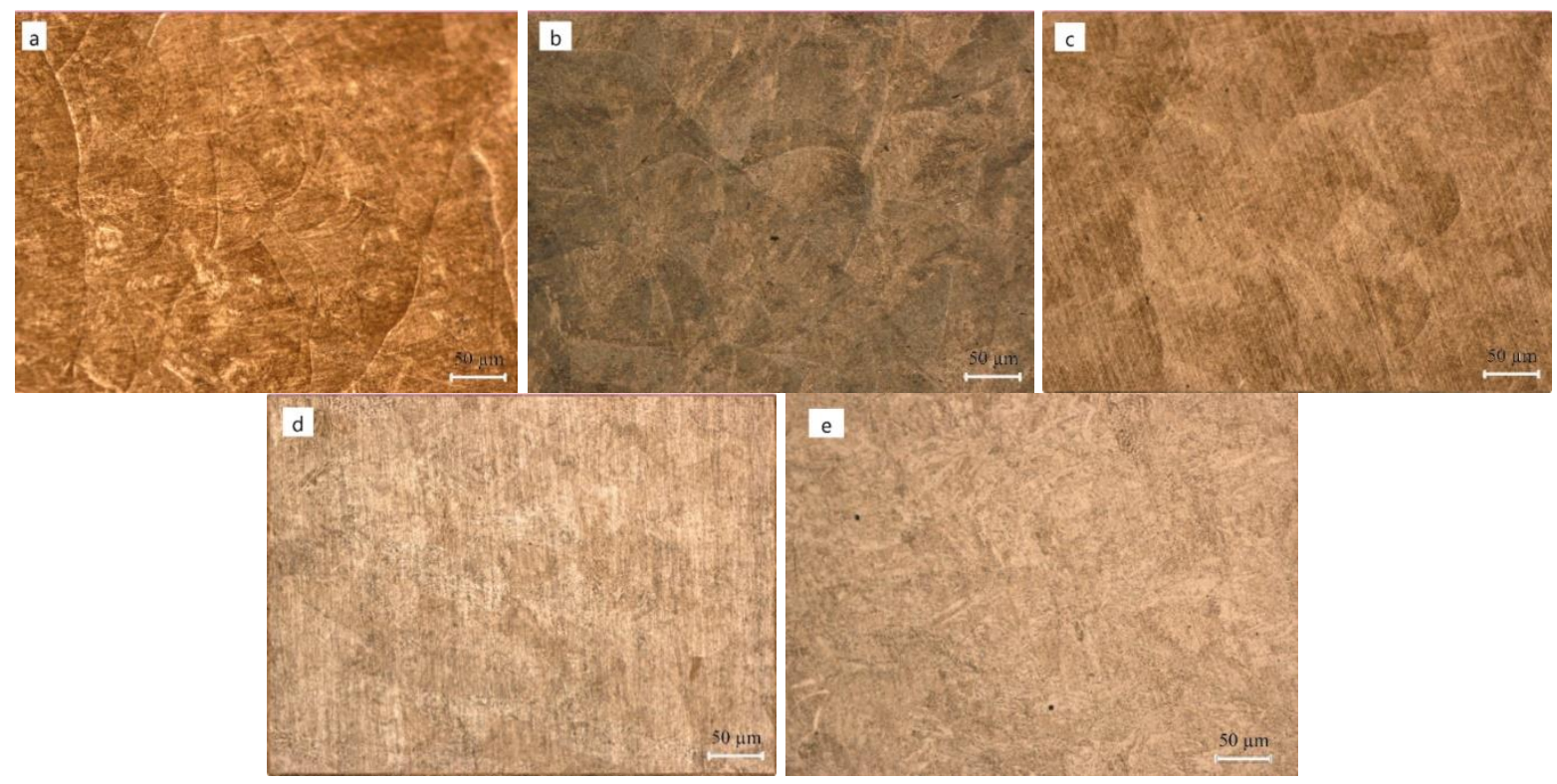

Figure 2: Optical images of samples (x100) that have been etched after heat treatment are shown; (a) ageing in an air atmosphere at $490{ }^{\circ} \mathrm{C}$ for 6 hours, (b) $\mathrm{Ar} / \mathrm{H}_{2}$ ageing at $490{ }^{\circ} \mathrm{C}$ for 6 hours, (c) $\mathrm{Ar} / \mathrm{H}_{2}$ at $520{ }^{\circ} \mathrm{C}$ for 6 hours, (d) $\mathrm{Ar} / \mathrm{H}_{2}$ ageing for 6 hours at $550{ }^{\circ} \mathrm{C}$, (e) $\mathrm{Ar} / \mathrm{H}_{2}$ at $580{ }^{\circ} \mathrm{C}$ for 6 hours.

\subsection{Scanning Electron Microscopy (SEM)}

SEM images of samples subjected to aging heat treatment at different temperatures for 6 hours are presented in Figure 4 (a)-(e). When we look at Figure 4a SEM images, we can see melt pool boundaries. We can say that the temperature of $490{ }^{\circ} \mathrm{C}$ is not enough to remove the meltpools. Figures 4 b show heat-treated samples in an $\mathrm{Ar} / \mathrm{H}_{2}$ atmosphere. Similar cellular structures are seen in the images at $520{ }^{\circ} \mathrm{C}$ and $550^{\circ} \mathrm{C}$, traces of molten pools have almost disappeared. In Figure 4 e, image at $580^{\circ} \mathrm{C}$ is shown. In the images, it was observed that the cellular structures decreased, and the grain sizes increased. The comment made in an article similar to our study is as follows; there is a noticeable difference in the melting pools with increasing temperature. As the temperature and heat-treatment time increases the strips, cellular structures and melt boundary do not completely disappear but visibility is reduced. The melt boundary begins to dissolve at $520{ }^{\circ} \mathrm{C}$; the long strips and cell walls split into short strips and spherical particles when the temperature increasing to $560{ }^{\circ} \mathrm{C}$ [11]. 

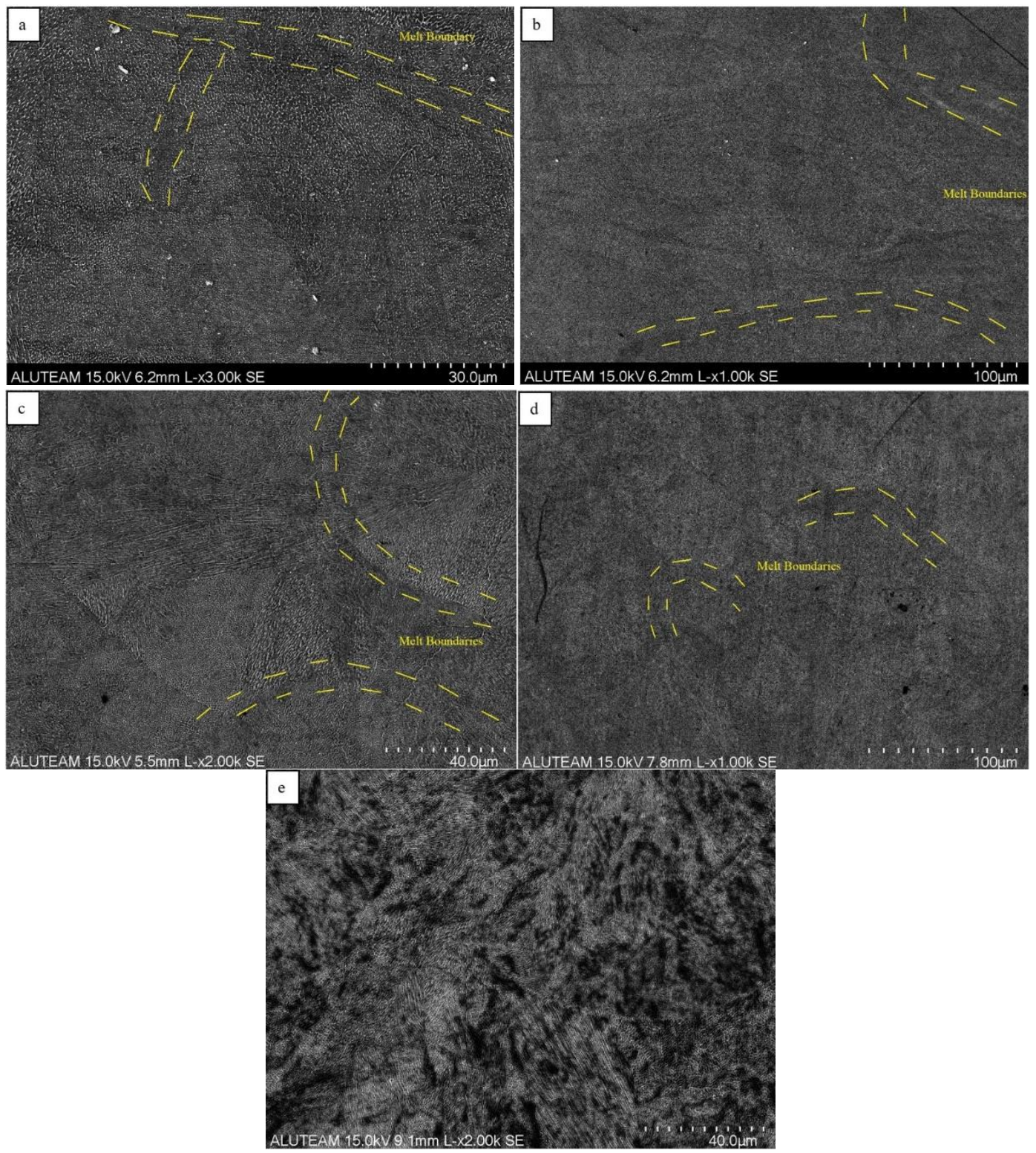

Figure 3: SEM images showing the microstructure of maraging steel formed with DMLS under different heat treatments (a) Air atmosphere at $490{ }^{\circ} \mathrm{C} / 6 \mathrm{~h}$, (b) $\mathrm{Ar} / \mathrm{H}_{2}$ atmosphere at $490{ }^{\circ} \mathrm{C} / 6 \mathrm{~h}$, (c) $\mathrm{Ar} / \mathrm{H}_{2}$ atmosphere at 520 ${ }^{\circ} \mathrm{C} / 6 \mathrm{~h},(\mathrm{~d}) \mathrm{Ar} / \mathrm{H}_{2}$ atmosphere at $550{ }^{\circ} \mathrm{C} / 6 \mathrm{~h}$, (e) $\mathrm{Ar} / \mathrm{H}_{2}$ atmosphere at $580{ }^{\circ} \mathrm{C} / 6 \mathrm{~h}$.

\subsection{XRD Analysis}

The XRD analysis results of the aging heat treatment in air and argon atmosphere for 6 hours at 490 degrees are shown in Figure 4. It is seen from the XRD graph that the samples are composed of martensite $(\alpha)$ phases in both atmospheres. When we look at the peak densities of the formed phases, it is seen that they are almost the same. In the study of Jun Song et al., experiments were carried out at different temperatures, heat treatments and times. These settled samples were subjected to solution treatment (ST) at $840{ }^{\circ} \mathrm{C}$ for 2 hours, followed by water cooling and direct aging treatment (AT) at $490{ }^{\circ} \mathrm{C}$ for 2 hours. An XRD model of the finished and heat-treated samples is presented, showing that the dominant microstructure for all conditions consists of the martensite $(\alpha)$ phase and that the heat treatment results in phase transformation. A significant number of martensite $(\alpha)$ phases were detected and the austenite $(\gamma)$ phase remained very low inside the constructed sample [18]. In a similar study by Chaolin Tan et al., the XRD results of the sample subjected to aging heat treatment at 490 degrees 6 hours in argon atmosphere and the XRD results of our $\mathrm{Ar} / \mathrm{H}_{2}-490-6$ sample are the same [19]. The data in this study show similar features to the data we found. In the study of Yuchao B. et al., the parameters of the aging heat treatment are similar to our study. In our study, XRD analyzes of increasing temperatures were not performed. In the study of Yuchao B. et al., the XRD phase analysis 
results of the aging heat treatment applied to the maraging steels produced by additive manufacturing with increasing temperature in 6 hours are given. When the result of the study was examined, it was observed that there was an increase in the intensity of the (200) peak of the $\gamma$-phase with increasing temperature. The (220) peak and (111) peak of the $\gamma$-phase appeared when the temperature reached $560{ }^{\circ} \mathrm{C}$. This indicates that the BCC matrix transforms into the FCC matrix during the aging heat treatment. It also indicates that high temperature induces austenite phase growth in other directions [11].

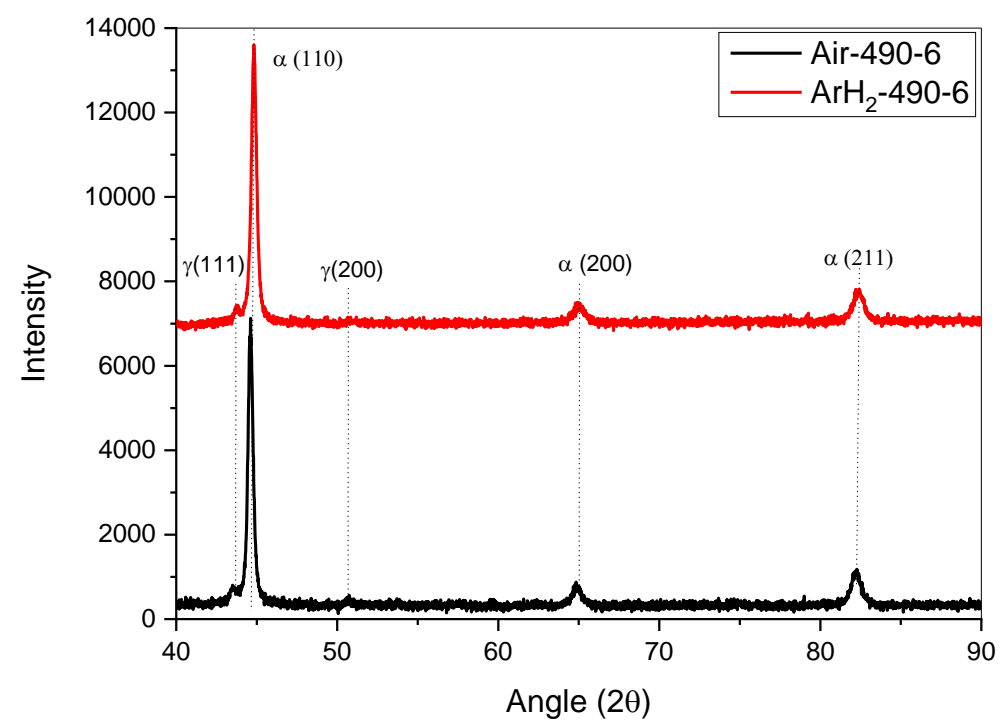

Figure 4: XRD results of samples heat-treated at $490{ }^{\circ} \mathrm{C} 6$ hours in the air and $\mathrm{Ar} / \mathrm{H}_{2}$ atmosphere.

\subsection{Hardness Test Results}

The results are shown in figure 5. Heat treatment was applied at $490^{\circ} \mathrm{C}$ in 2 different atmospheres for 6 hours. There is a small difference between the hardness values of the sample subjected to aging heat treatment in an air atmosphere and the sample subjected to aging heat treatment in an $\mathrm{Ar} / \mathrm{H}_{2}$ atmosphere. The hardness value of maraging steel heat-treated in the air atmosphere is $587 \mathrm{HV}$. The hardness of the sample, which was heat-treated at $490^{\circ} \mathrm{C}$ for 6 hours in $\mathrm{Ar} / \mathrm{H}_{2}$ atmosphere, is $567 \mathrm{HV}$ The hardness of the sample aged in the air atmosphere is slightly higher. The reason for this can be explained based on XRD analysis. It may be negatively affected hardness that the lower peak of the $\mathrm{Fe}$ phase (a110) at 45 degrees in the $\mathrm{Ar} / \mathrm{H} 2-490-6$ sample is slightly more transform from martensite to austenite form.

In a similar study by Stornelli et al., each sample was first applied to solution heat treatment at $940{ }^{\circ} \mathrm{C}$ for 2 hours, and then aging heat treatment was applied at different temperatures and times. The parameters selected for the aging heat treatment in this study are similar to our study. As a result of the study, the decrease in hardness values with increasing temperature is close to our results. They interpreted the decreasing hardness with increasing temperature as follows; The best condition of aging treatment is $490{ }^{\circ} \mathrm{C}$ and 6 hours. As the temperature increased, the hardness value deteriorated. As it is known from the literature, with a high treatment temperature or for a long aging time negatively affected physical properties. This condition lead to degradation of the strength of the maraging steel. The intermetallic compounds become coarser and/or the metastable martensite transforms into austenite when the heat treatment applied above $490^{\circ} \mathrm{C}$ [15]. That phenomena had occurred in our study as the hardness decreases by about $50 \mathrm{HV}$, going from $583 \mathrm{HV}$ for a temperature of $490^{\circ} \mathrm{C}$, to $532 \mathrm{HV}$ at $550{ }^{\circ} \mathrm{C}$. 


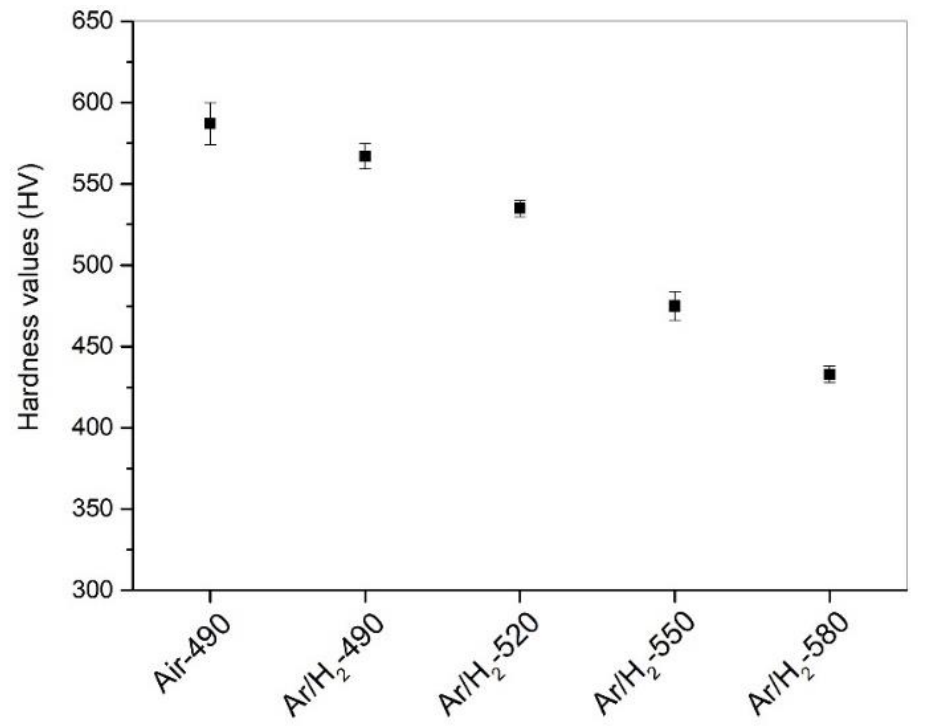

Figure 5: Hardness values at different temperatures

\section{CONCLUSION}

This study investigates the effects of aging processes applied in different atmospheres at different temperatures of maraging steels produced by the Direct Metal Laser Sintering (DMLS) method. 2 different atmospheres were used as atmosphere: $90 \% \mathrm{Ar}-10 \% \mathrm{H}_{2}$ gas mixture and air. $\mathrm{Ar} / \mathrm{H}_{2}$ gas atmosphere was used as the atmosphere; the temperatures are $490^{\circ} \mathrm{C}, 520^{\circ} \mathrm{C}, 550^{\circ} \mathrm{C}, 580^{\circ} \mathrm{C}$ and aging heat treatment process was applied in 6 hours. In the air atmosphere, it was aged for 6 hours at $490{ }^{\circ} \mathrm{C}$. The following conclusions can be drawn from this study:

1. The hardness of the sample, which is aged in an air atmosphere, is slightly higher. If we compare the samples that have undergone aging heat treatment in an $\mathrm{Ar} / \mathrm{H}_{2}$ atmosphere in general, we can say that the hardness value decreases with increasing temperature. In short, increasing temperature negatively affects the hardness property of the sample.

2. When we look at these two different atmosphere samples SEM and OM images, we can see melt pools left over from additive manufacturing at $490^{\circ} \mathrm{C}$. With the increasing temperature, traces of molten pools have almost disappeared.

3. The XRD analysis results of the samples, which ageing heat treatment in air and $\mathrm{Ar} / \mathrm{H}_{2}$ atmosphere for 6 hours at 490 degrees, is seen from the XRD graph that the samples are composed of martensite $(\alpha)$ phases in both atmospheres. When we look at the peak densities of the formed phases, it is seen that they are almost the same.

\section{ACKNOWLEDGMENTS}

The authors acknowledge the financial support provided by TUBITAK (The Scientific and Technological Research Council of Turkey) with 1002- R\&D Funding Programme (120M953).

\section{REFERENCES}

1. Godec, M., Donik, C. Kocijan, A., Podgornik, B., Skobir Balantic, D. A.. "Effect of post-treated lowtemperature plasma nitriding on the wear and corrosion resistance of 316L stainless steel manufactured by laser powder bed fusion”, Additive Manufacturing, Vol.32, Pages:1-9, 2020.

2. Herzog, D., Seyda, V., Wycisk, E., Emmelmann, C. "Additive manufacturing of metals", Acta Materialia, Vol.117, Pages:371-392, 2016.

3. Çevik Z.A, Özsoy K., Erçetin A, The Effect of Machining Process on The Pyhsical and Surface Morphology of Ti6A14V Specimens Produced Through Powder Bed Fusion Additive Manufacturing” Int. J. of 3D Printing Tech. Dig. Ind., Vol.5 Issue 2, Pages:187-194, 2021. 
4. Casalino, G., Campanelli, S.L., Contuzzi, N., Ludovico, A.D "Experimental investigation and statistical optimisation of the selective laser melting process of a maraging steel", Optics \&amp; Laser Technology, Vol.65, Pages:151-158, 2015.

5. ASTM F2792, F2792-12a - Standard Terminology for Additive ManufacturingTechnologies, ASTM B. Stand, Pages:10-12, 2013.

6. Özer G., "Eklemeli üretim teknolojileri üzerine derleme” NÖHÜ Müh. Bilim. Derg. / NOHU J. Eng. Sci., Vol.9 Issue 1, Pages:606-621, 2020

7. Li, X., \& Yin, Z., Reverted austenite during aging in $18 \mathrm{Ni}(350)$ maraging steel. Materials Letters, Vol.24 Issue 4, Pages:239-242, 1995

8. Mooney, B., Kourousis, K. I., Raghavendra, R., "Plastic Anisotropy of additively manufactured maraging steel: Influence of the build orientation and heat treatments", Additive Manufacturing, Vol.25, Pages:19-31, 2018.

9. I. Adam, W. B. du Preez, J. Combrinck, M. Zwemstra, "Conformal cooling channel design for direct metal sintering of maraging steel injection mould inserts", Pages:1-11, 2019.

10. dos Reis, A. G., Reis, D. A. P., Abdalla, A. J., Otubo, J., Zepka, S., Couto, A. A., \& Scheid, V. H. B., "Effect of simultaneous plasma nitriding and aging treatment on the microstructure and hardness of maraging 300 steel”, Advanced Structured Materials, Vol.70, Pages:277-284, 2015.

11. Bai, Y., Wang, D., Yang, Y., \& Wang, H., "Effect of heat treatment on the microstructure and mechanical properties of maraging steel by selective laser melting", Materials Science and Engineering A, Vol.760, Pages:105-117, 2015

12. Yan, X., Huang, C., Chen, C., Bolot, R., Dembinski, L., Huang, R., Ma, W., Liao, H., \& Liu, M., “Additive manufacturing of WC reinforced maraging steel 300 composites by cold spraying and selective laser melting”, Surface and Coatings Technology, Vol.371, Pages:161-171, 2019.

13. Aydın İ., "Investigation of Effects of Heat Treatment Process on Microstructural and Mechanical Properties of Additively Manufactured 18Ni300 Maraging Steel", Graduate thesis, Middle East Technical University, Ankara, 2020

14. Gordon Jones, "https://all3dp.com/2/direct-metal-laser-sintering-dmls-simply-explained/”, 2021.

15. Stornelli, G., Gaggia, D., Rallini, M., \& di Schino, A., "Heat treatment effect on maraging steel manufactured by laser powder bed fusion technology: Microstructure and mechanical properties", Acta Metallurgica Slovaca, Vol.27 Issue 3, Pages:122-126, 2021.

16. EOS, "Material Data Sheet", eos.info/03_system-related-assets/material-related-contents/metal-materialsand-examples/metal-material-datasheet/werkzeugstahl_ms1_cx/ms1/ms-ms1m280_m290_400w_material_data_sheet_05-14_en.pdf”, Erişim:21.12.2016, 2021

17. Gökhan Özer, Ahmet Karaaslan, "A Study on the Effects of Different Heat-Treatment Parameters on Microstructure-Mechanical Properties and Corrosion Behavior of Maraging Steel Produced by Direct Metal Laser Sintering”, Steel research international, Vol. 91 Issue 10, Pages:1-8 ,2020.

18. Song, J., Tang, Q., Feng, Q., Ma, S., Setchi, R., Liu, Y., Han, Q., Fan, X., \& Zhang, M., "Effect of heat treatment on microstructure and mechanical behaviours of $18 \mathrm{Ni}-300$ maraging steel manufactured by selective laser melting", Optics and Laser Technology, Vol.120, 2019.

19. Tan, C., Zhou, K., Ma, W., Zhang, P., Liu, M., \& Kuang, T., "Microstructural evolution, nanoprecipitation behavior and mechanicalproperties of selective laser melted high-performance grade 300maraging steel" Materials and Design, Vol.134, Pages:23-34, 2017. 